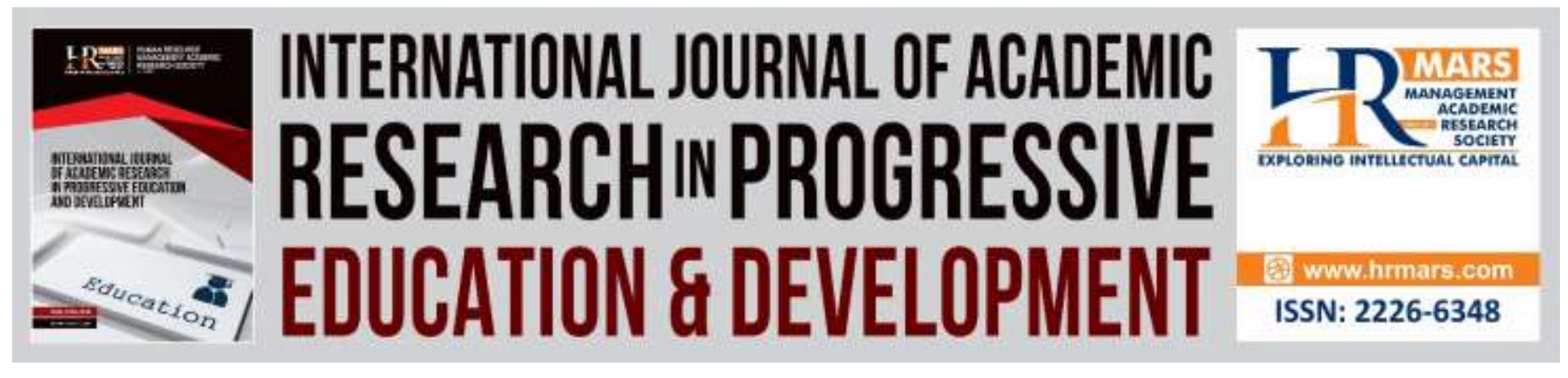

\title{
The Effect of Motivation on Academic Achievement among the Jordanian Universities Student
}

\author{
Ahmad Al-oqleh, Kamarul Shukri Mat Teh
}

To Link this Article: http://dx.doi.org/10.6007/IJARPED/v8-i3/6408

DOI: $10.6007 /$ IJARPED/v8-i3/6408

Received: 18 July 2019, Revised: 11 August 2019, Accepted: 02 September 2019

Published Online: 28 September, 2019

In-Text Citation: (Al-oqleh \& Teh, 2019)

To Cite this Article: Al-oqleh, A., \& Teh, K. S. M. (2019). The Effect of Motivation on Academic Achievement among the Jordanian Universities Student. International Journal of Academic Research in Progressive Education and Development, 8(3), 267-278.

Copyright: (C) 2019 The Author(s)

Published by Human Resource Management Academic Research Society (www.hrmars.com)

This article is published under the Creative Commons Attribution (CC BY 4.0) license. Anyone may reproduce, distribute, translate and create derivative works of this article (for both commercial and non-commercial purposes), subject to full attribution to the original publication and authors. The full terms of this license may be seen

at: http://creativecommons.org/licences/by/4.0/legalcode

Vol. 8(3) 2019, Pg. 267 - 278

http://hrmars.com/index.php/pages/detail/IJARPED

JOURNAL HOMEPAGE

Full Terms \& Conditions of access and use can be found at http://hrmars.com/index.php/pages/detail/publication-ethics 


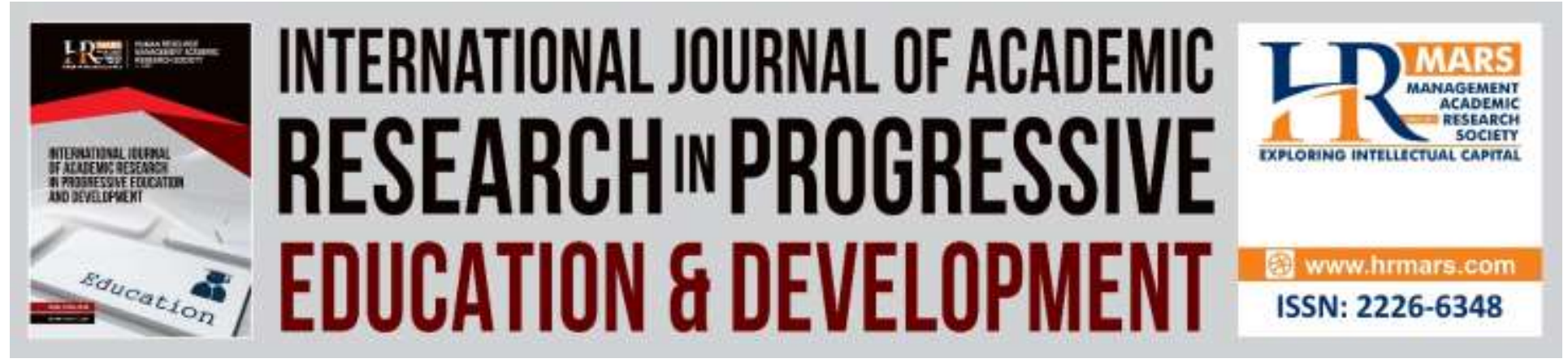

\title{
The Effect of Motivation on Academic Achievement among the Jordanian Universities Student
}

\author{
Ahmad Al-oqleh, Kamarul Shukri Mat Teh \\ Faculty of Islamic Contemporary Studies, University Sultan Zainal Abidin, Gong Badak Campus, \\ 21300 Kuala Terengganu, Malaysia. \\ Email: kamarul@unisza.edu.my, ahmadshqairat@yahoo.com
}

\begin{abstract}
The study aimed to investigate the effect of the motivation on academic achievement among the Jordanian universities student. The sample consisted of (440) first academic year students. this study follows the quantitative study approach. The study employed the Stratified Random Sampling and Simple Random probability sampling techniques. The results showed a level of students was a moderate generally in their motivation level, results also showed a significant difference between the degrees of students with high achievement on the test compared with the degrees of students with moderate and low achievement, there is a significant difference in the achievement motivation level of male and female. The mean level of females is higher than males. Intrinsic and extrinsic motivation had a positive predictive effect on academic achievement among the Jordanian students in their first academic year. According to these findings, the study recommended activating the blended learning strategies in teaching.

Keywords: Academic Achievement, Motivation, Intrinsic Motivation, Extrinsic Motivation.
\end{abstract}

\section{Introduction}

Strayhorn (2018) Mention that the student's academic performance and graduation rates have been the area of interest for higher education institutions, Investigation of factors related to the academic performance of university students become a topic of growing interest in a higher educational circle, many recent studies were carried out to explore factors affecting university student's academic performance. Zheng et al. (2014) reported that Student performance is affected by different factors such as learning abilities, gender and race. Mega, et al. (2014) concluded that family income level, attending full time, receiving grant aid and completing advanced level classes in high school having statistically significant effects on college persistence among first-generation college students.

Currently, various indicators are used to interpret academic performance based on grades, length of stay at the university, levels of competence achieved, etc.. However, most are not for predictive purposes and are only known after time has passed more than prudential that 
although it has allowed building a history of the academic trajectory of a student, does not allow remedial actions. Many universities nowadays face social and governmental pressure that demands not only quality training, but also that their training process is consistent with the admission requirements included in the selection process, considering that, in theory, the students have been selected because they are able to successfully complete university studies (Tomlinson, 2017).

For that, the weakness of educational achievement is one of the challenges faced by parents and teachers. Its attainment is a long-standing subject because it has many consequences for the future of an entire generation. The biggest challenge is to find suitable solutions to solve poor achievement and to know the real causes. This problem cannot be resolved without concerted efforts and the radical solution of the academic achievement weakness through effective vocational educational methods, without solving the problem by another problem, like psychological and physical punishment, which is practiced by some parents and teachers on the weakness in the academic achievement of the student (Tomlinson, 2017).

Over the years, researches have revealed that academic achievement has numerous determinant factors ranging from socioeconomic status, students employment status, learning disabilities, Students Interest, attitude, Guidance and counseling, teaching methods, Gender continuous assessment. Due to the quest for the better academic performance of students at all levels of education (Harackiewicz, 2014).

Even though this research puts into questions whether gender differences still exist in academic achievement, many researchers are still finding differences in performance as well as general interest in areas related to math and science and education. Separately, the examinations of gender and achievement differences in motivation have histories that span at least three decades (Kessels, et al. 2015). The Important of this study comes to discusses the differences of the academic achievement among the Jordanian universities students according to gender in their motivation in the first academic year and how we can predict by their academic achievement depending on their motivation there are inconclusive results over which individual factors successfully predict academic performance, elements such as metacognition, motivation, test anxiety, environment, cognition, intelligence, and emotions require consideration when developing models of academic achievement. In addition, the questions of what skills are the most strongly associated with academic learning motivation, this study examines the predictive validity of a measure of motivation components tasks in academic achievement. We used random effect models and fixed effects models to examine the predictive relations of academic outcomes during the first academic year (Cerasoli, et al, 2014).

\section{Problem Statement}

Some gaps were spotted in the existing literature. Thus, there is a lack of research on the role of metacognition and motivation as factors could be an effect on academic achievement. However, a majority of studies focused on this topic are confined to one dimension of motivation in terms of the effect on achievement has been measured in general case, in the area of Jordan never these factors were taken in a group to examine any direct effect on academic achievement in 
one group. Therefore, the outcomes are still ambiguous and unsatisfied especially in the first academic year as it is. More specifically, this study aims to provide viewpoints and empirical outcomes to shed light on this topic. Moreover, although the effect of motivational attributes on academic achievement has been previously explored, much research does not simultaneously investigate attributes external to these set categories to obtain a more comprehensive understanding of the gender differences in motivation (Pirmohamed, Debowska, \& Boduszek, 2017). Request more research revolving around the impact of motivational constructs on learning outcomes is required to unearth the meaning and implications of motivational constructs and motivation theories across cultures.

\section{Research Questions}

1. What is the motivation level among Jordanian university students?

2. Are there any significant relationship between gender and motivation among the university students?

3. Are there any significant differences in their academic achievement according to their level of motivation?

\section{Research Objectives}

1- To examine the motivation level among the Jordanian universities students.

2- To examine if are there any significant relationship between gender and motivation among the university students.

3- To identify any significant differences in their academic achievement according to their level of motivation.

\section{Research Hypotheses}

Ho1: There is no significant difference in the relationship between gender and motivation among the universities students.

Ho2: there are no any significant differences in their academic achievement according to their level of motivation.

\section{Significance of the Study}

The significance of this study lies in its examination the effect role of motivation on academic achievement among the students in the first academic year in the faculty of education in Jordan universities. Also, to examine the level of the students in motivation on academic achievement, and to identify if there are significant differences in motivation on academic achievement do exist among the students according to gender in the first academic year and whether the pattern of differences varies by region. This represents an important step in motivational and metacognition literature, if they are found will be illuminated by within-group comparisons not an across-group comparison. Additionally, the aim of this study is to examine the perception of the students towards metacognition and motivation practices and to determine whether or not of these theories practices lead to enhance academic achievement and improved student's competence. 
Vol. 8, No. 3, 2019, E-ISSN: 2226-6348 @ 2019 HRMARS

\section{The Scope of the Study}

This study's scope is confined to the students in the first academic year of Jordanian universities (Al-Yarmouk, Al-albeit, Al-Tefillah and University of Jordan). The population of this study contains students from one main faculty (faculty of education), which consist all of the fields of education to obtain empirical evidence on the role of metacognition and motivation on academic achievement and the relationship between metacognition and motivation.

\section{Size of Sample}

The sample size for this study consists of 384 respondents selected from the target population of 3,500 and it was calculated according to a table developed by Krejcie and Morgan (1970). However, the sample size can be increased to 440 respondents to avoid any bias or ambiguity. The study employed the Stratified Random Sampling (proportional random sampling techniques) and Simple Random probability sampling techniques. In Stratified Random Sampling or proportional random sampling technique, the number of samples will be divided according to the number of students from each university to determine the exact number of questionnaires to be distributed. Thus, after the division process, this study will employ the simple random technique. In simple random sampling, every sample in the population has a known and equal chance of being selected as a subject (Alvi, 2016).

\section{Research Instruments}

The questionnaire was the instrument used for collecting data and were separated into three parts. Part (A) has captured the respondent's Grade Point Average (GPAs) and information about the respondents. While, Part (B) has captured information about motivation.

The participants completed two scales about their perceived use of motivation. the motivation was measured using the MC5 scale. Each measure was modified to address questions of perceived motivation in four different universities subjects in the faculty of education. The answers given to corresponding questions for each subject were compared to identify the degree of generalizability across domains; Responses to each question were reported using a five-point Likert scale, ranging from "Never" to "Always" for metacognition scale, For measuring the motivation a Five-point Likert Scale used, the respondents were asked to indicate the extent to which they agree/disagree with the statements.

Table 1.1 shows the Likert scale measurements for motivation.

\begin{tabular}{|c|c|c|c|c|}
\hline $\begin{array}{c}\text { Strongly } \\
\text { Disagree }\end{array}$ & Disagree & Neutral Agree & Agree & $\begin{array}{c}\text { Strongly } \\
\text { Agree }\end{array}$ \\
\hline 1 & 2 & 3 & 4 & 5 \\
\hline
\end{tabular}

\begin{tabular}{|c|c|c|}
\hline Low & Moderate & High \\
\hline $1-2.33$ & $2.34-3.37$ & $3.68-5.00$ \\
\hline
\end{tabular}


INTERNATIONAL JOURNAL OF ACADEMIC RESEARCH IN PROGRESSIVE EDUCATION AND DEVELOPMENT

Vol. 8, No. 3, 2019, E-ISSN: 2226-6348 @ 2019 HRMARS

Table 1.2 Instruments of Motivation Questionnaire

\begin{tabular}{|l|l|c|c|}
\hline S/N & \multicolumn{1}{|c|}{ Variable } & Number Of Questions & Source \\
\hline 1 & Intrinsic motivation & 10 & $\begin{array}{c}\text { Adjusted by } \\
\text { Safieh hussien, Abdelnaser Al- } \\
\text { Jarrah, 2012, } \\
\text { Created based on } \\
\text { Vallerand et al.(2002 }\end{array}$ \\
\hline 2 & Extrinsic motivation & 11 & \begin{tabular}{c} 
Sand \\
\hline
\end{tabular}
\end{tabular}

Motivation (21 items) Divided into two dimensions were measured using intrinsic motivation (10 items) and extrinsic motivation (11 items), recommended that an alpha coefficient that is greater than 0.7 is generally considered acceptable. Construct reliability is frequently used with the Structural Equation Model.

\section{Validity and Reliability of Motivation scale Validity of Motivation Scale}

The first category is content validity; this category looks at whether the instrument adequately covers all the content that it should with respect to the variable. In other words, does the instrument cover the entire domain related to the variable, or construct it was designed to measure for. A subset of content validity is face validity, where experts are asked their opinion about whether an instrument measures the concept intended. Construct validity refers to whether you can draw inferences about test scores related to the concept being studied.

Where all the questions of the scales which were addressed in the current study were taken from previous studies, these questions were stated as reliable and valid to measure constructs of the phenomenon that they intend to investigate. They were taken from the previous literature which shared and measured the similar context of the current research. This may provide more validity of the items used in this study. The researcher requested six academic staff from Al-yarmouk University faculty of education to re-revision the scales to ensure its fit for this study all answers were the scales are fit for the current study.

\section{Reliability of Motivation Scale}

Table (3) shows the Cronbach' Alpha value which rang $(0.70-0.81)$, and total questionnaire items was (0.86), this indicate to acceptable Cronbach' Alpha value for each domain, whenever Cronbach' Alpha value is acceptable if it's more than (0.60). 
Table (1.3) Cronbach' Alpha Value for Each Domain

\begin{tabular}{|l|l|}
\hline Domain & Cronbach' Alpha value \\
\hline Intrinsic motivation & 0.70 \\
\hline Extrinsic motivation & 0.81 \\
\hline Motivation scale & 0.86 \\
\hline
\end{tabular}

This study used (SPSS) the Statistical Package for Social Sciences for data analysis. Data were examined for outliers prior to the actual analysis, after which the data was transformed, computed, and recorded with new labels. In particular, nominal scale data was employed based on the study variables.

\section{Procedures of the Study}

After reviewing the research literature and previous studies related to the subject of the study, the study tools were prepared and verified the validity and reliability of the study, and then the study community was determined from the students in the first academic year of four Jordanian universities, Finally, the data was entered into the computer memory, and the appropriate statistical analysis was carried out using SPSS and the results were extracted, interpreted and discussed.

First: the results related to the first question which states that "what is the motivation level among Jordanian university students?'

To answer the second question that tackles the level of motivation of students based on the overall scale and its two factors, the researcher has calculated the mean, standard deviation and percentage of the student's scores for each of the all factors in the Motivation.

Motivation perceptions of the students are measures by using 21 questions in Likert-5 style. In addition the questions are asking about two dimensions of intrinsic, regulation by 10 questions, and extrinsic by 11 questions. Figure 4.9 shows info graphic of motivation and its dimensions and Table 4.4 shows the related descriptive scores. Students' perception of motivation is moderate satisfaction with score of 3.48 (68\%). In addition there are differences between intrinsic and extrinsic perceptions, because the student shows a higher level of satisfaction for extrinsic motivation with rate of $74 \%$ compared to $63 \%$ for intrinsic motivation.

Table Error! No text of specified style in document..1: Desriptives of Motivation and its

Dimensions

\begin{tabular}{|c|c|c|c|}
\hline & Mean & Std. Deviation & Percentage \\
\hline Motivation_Intrinsic & 3.1621 & .84152 & 63.242 \\
\hline Motivation_Extrinsic & 3.6917 & .69570 & 73.834 \\
\hline Motivation & 3.4269 & .76738 & 68.538 \\
\hline
\end{tabular}


Vol. 8, No. 3, 2019, E-ISSN: 2226-6348 C 2019 HRMARS

Second: the results related to the second hypothesis which states "there is no significant difference in the relationship between gender and motivation among the universities students".

Descriptive statistics and independent t-test were used to determine whether a difference existed in the academic motivations of female and male students. The analysis showed statistically significant differences between male and female students at $p=0.05$ confidence level in all of the motivational subscales displayed in Table.

Info graphic of the relation is proposed in Figure 4.12, in which gender two groups could be different for motivation, intrinsic motivation, and extrinsic. As seen in Tables 4.8 and 4.9, this study found that male group participants had statistically significantly lower motivation (3.29 \pm 0.78 ) based on their answers of the survey compared to female group $(3.57 \pm 0.73), t(438)=$ $4.022, p=0.000$ and Levene's test score confirm the result with a rejected $p$-value $=0.191$.

Table 1.5: Independent Sample T-test of Gender - Motivation Relation

\begin{tabular}{|c|c|c|c|c|c|c|}
\hline \multirow{2}{*}{} & $\begin{array}{c}\text { Levene's Test for } \\
\text { Equality of } \\
\text { Variances }\end{array}$ & \multicolumn{4}{|c|}{ t-test for Equality of Means } \\
\cline { 2 - 7 } & $\mathrm{F}$ & Sig. & $\mathrm{t}$ & $\mathrm{df}$ & $\begin{array}{c}\text { Sig. (2- } \\
\text { tailed) }\end{array}$ & $\begin{array}{c}\text { Mean } \\
\text { Difference }\end{array}$ \\
\hline Motivation & 1.719 & .191 & -4.022 & 438 & .000 & -.28543 \\
\hline Intrinsic Motivation & 1.113 & .292 & -3.863 & 438 & .000 & -.30518 \\
\hline Extrinsic Motivation & 3.043 & .082 & -4.001 & 438 & .000 & -.26095 \\
\hline
\end{tabular}

Table Error! No text of specified style in document..6: Mean Values of Motivation based on Gender

\begin{tabular}{|c|c|c|c|c|}
\hline & Gender & $\mathrm{N}$ & Mean & Std. Deviation \\
\hline \multirow{3}{*}{ Motivation } & Male & 220 & 3.2854 & .78136 \\
\cline { 2 - 5 } & Female & 220 & 3.5685 & .72777 \\
\hline \multirow{3}{*}{ Intrinsic Motivation } & Male & 220 & 3.0095 & .84873 \\
\cline { 2 - 5 } & Female & 220 & 3.3147 & .80772 \\
\hline \multirow{2}{*}{ Intrinsic Motivation } & Male & 220 & 3.5613 & .71646 \\
\cline { 2 - 5 } & Female & 220 & 3.8222 & .65015 \\
\hline
\end{tabular}

For intrinsic motivation, this study found that male group participants had statistically significantly lower intrinsic motivation (3.01 \pm 0.85 ) based on their answers of the survey compared to female group $(3.31 \pm 0.81), t(438)=3.868, p=0.000$ and Levene's test score confirm the result with a rejected $p$-value $=0.292$. 
For extrinsic motivation, this study found that male group participants had statistically significantly lower extrinsic motivation $(3.56 \pm 0.71)$ based on their answers of the survey compared to female group $(3.82 \pm 0.65), t(438)=4.001, p=0.000$ and Levene's test score confirm the result with a rejected $p$-value $=0.082$.

Based on the above discussions, motivation, intrinsic motivation, and extrinsic have mean value differences based of the gender of the students. Hypothesis "Ho1: there is no significant difference in the relationship between gender and motivation among the universities students." is rejected.

This finding was consistent with the results of studies found that female students are significantly more motivated than their male counterparts, Sharma, D., \& Sharma, S. (2018); Homan and Asgari Bahrani and Roohi \& Asayesh (2012) ; Makhlough, A., Siamian, H., Asrami, F. N., Khademloo, M., \& Esmaeili, H. (2016).; Roohi, G. H., Asayesh, H., Bathai, S. A., Shouri Bidgoli, A. R., Badeleh, M. T., \& Rahmani, H. (2013). McGehee, N. G., Kim, K., \& Jennings, G. R. (2007); , Vallerand et al. (1992), Hegarty, N. (2010) .

Third: the results related to the third hypothesis which states "there are no any significant differences in their academic achievement according to their level of motivation" Info graphic of the relation is proposed in Figure 4.15, in which categories of grade could be different for motivation level. Table 4.13 and Figure 4.16 show the frequencies of motivation based on three level categories, low, medium, and high. The majority have high metacognition with score of $52 \%$, followed by Medium (39.3\%), then low (8.6\%).

Table Error! No text of specified style in document..7: Frequency Distribution of Motivation

\begin{tabular}{|c|c|c|c|c|c|}
\hline \multicolumn{2}{|c|}{} & Frequency & Percent & Valid Percent & $\begin{array}{c}\text { Cumulative } \\
\text { Percent }\end{array}$ \\
\hline \multirow{4}{*}{ Motivation } & Low & 38 & 8.6 & 8.6 & 8.6 \\
\cline { 2 - 6 } & Medium & 173 & 39.3 & 39.3 & 48.0 \\
\cline { 2 - 6 } & High & 229 & 52.0 & 52.0 & 100.0 \\
\cline { 2 - 6 } & Total & 440 & 100.0 & 100.0 & \\
\hline
\end{tabular}

As seen in Tables 4.14 and 4.15, there was a statistically significant difference between groups as determined by one-way ANOVA $(F(2,437)=270.139, p=0.000)$. A Tukey post hoc test revealed that score was statistically significantly higher for high- motivation $(1.895 \pm 0.126, p=0.000)$ and medium- motivation $(1.521 \pm 0.073, p=0.000)$ compared to low- motivation $(0.374 \pm 0.129, p=$ 0.011). There was statistically significant difference between the high- motivation and mediummotivation groups $(p=0.000)$. 
INTERNATIONAL JOURNAL OF ACADEMIC RESEARCH IN PROGRESSIVE EDUCATION AND DEVELOPMENT

Vol. 8, No. 3, 2019, E-ISSN: 2226-6348 @ 2019 HRMARS

Table 1.8: One Way ANOVA of Motivation - Grade Relation

\begin{tabular}{|c|c|c|c|c|c|}
\hline & Sum of Squares & df & Mean Square & F & Sig. \\
\hline Between Groups & 281.265 & 2 & 140.632 & 270.139 & .000 \\
\hline Within Groups & 227.499 & 437 & .521 & & \\
\hline Total & 508.764 & 439 & & & \\
\hline
\end{tabular}

Table 1.9: Post Hoc Tests of Motivation - Grade Relation

\begin{tabular}{|c|c|c|c|c|c|}
\hline \multicolumn{6}{|c|}{ Dependent Variable: Grade } \\
\hline & Motivation_Categories & Motivation_Categories & \begin{tabular}{|c} 
Mean \\
Difference (I- \\
J)
\end{tabular} & $\begin{array}{l}\text { Std. } \\
\text { Error }\end{array}$ & Sig. \\
\hline \multirow{6}{*}{ Tukey HSD } & \multirow{2}{*}{ Low } & Medium & $-.374 *$ & .129 & .011 \\
\hline & & High & $-1.895^{*}$ & .126 & .000 \\
\hline & \multirow{2}{*}{ Medium } & Low & $.374^{*}$ & .129 & .011 \\
\hline & & High & $-1.521^{*}$ & .073 & .000 \\
\hline & \multirow{2}{*}{ High } & Low & $1.895^{*}$ & .126 & .000 \\
\hline & & Medium & $1.521^{*}$ & .073 & .000 \\
\hline \multirow{6}{*}{ Bonferroni } & \multirow{2}{*}{ Low } & Medium & $-.374^{*}$ & .129 & .012 \\
\hline & & High & $-1.895^{*}$ & .126 & .000 \\
\hline & \multirow{2}{*}{ Medium } & Low & $.374^{*}$ & .129 & .012 \\
\hline & & High & $-1.521^{*}$ & .073 & .000 \\
\hline & \multirow{2}{*}{ High } & Low & $1.895^{*}$ & .126 & .000 \\
\hline & & Medium & $1.521^{*}$ & .073 & .000 \\
\hline
\end{tabular}

Based on the above discussions, grade values have differences based of the motivation level of the students. Hypothesis "Ho4: there are no significant differences in their academic achievement according to the level of motivation." is rejected.

The findings of the study indicated that extrinsic motivation had a moderate predictive effect on academic achievement for Jordanian students in the first academic year at university. In other words, students who study for extrinsic reasons have poorer academic achievement than do adolescents with lower intrinsic motivation. However, extrinsic motivation was not a significant predictor of academic achievement for students in Jordan. The negative association between 
Vol. 8, No. 3, 2019, E-ISSN: 2226-6348 C 2019 HRMARS

extrinsic motivation and academic achievement is very well documented in the burgeoning literature on extrinsic motivation (Becker et al. 2010; Lepper et al. 2005; Wolters et al. 1996).

According to the research, there is any significant difference in students' motivation according to grades. It is expected that students have positive experiences with lessons and become more motivated. In the current study, however, it was found that levels of students' intrinsic and extrinsic motivation do differ according to grades.

\section{Directions for Future Research}

Motivation practices examined in this study and their impact on academic achievement as well as the role of gender the variables were present in the literature until this study. This study thus minimizes a gap in the literature concerning this fact. Limitations of this study, along with questions that have emerged from this study, could create opportunities for future research. and there are as follows:

1. The findings supported the importance of motivation in improving academic performance and its significant impact on students. Nevertheless, the importance of each metacognition and motivation practice in improving academic achievement, differences in these impacts, the differences of gender on all of these variables still remain unresolved. These factors need addressing in the context of Jordanian universities as these universities face dynamic competition that relates to the above issues.

2. More studies could be conducted in terms of motivation within other sectors in Jordan as private universities and countries that have different cultures.

3. Future studies could focus on the impact of motivation as well as the relevance of gender using qualitative research to know what the opinion of students about the results of low academic achievement and the role of metacognition and motivation in learning.

Moreover, future studies could focus on other factors that influence academic achievement; such as habits of study, meta-comprehension, meta-memory, compassion, satisfaction, causal attribution.

Acknowledgement: I express my deepest gratitude to Center for Research Excellence \& Incubation Management (CREIM), Universiti Sultan Zainal Abidin for supporting our intellectual endeavor.

\section{References}

Awang, Z. (2012). Structural equation modeling using AMOS graphic. Penerbit Universiti Teknologi MARA.

Alvi, M. (2016). A manual for selecting sampling techniques in research.

Cerasoli, C. P., Nicklin, J. M., \& Ford, M. T. (2014). Intrinsic motivation and extrinsic incentives jointly predict performance: A 40-year meta-analysis. Psychological bulletin, 140(4), 980. 
Harackiewicz, J. M., Canning, E. A., Tibbetts, Y., Giffen, C. J., Blair, S. S., Rouse, D. I., \& Hyde, J. S. (2014). Closing the social class achievement gap for first-generation students in undergraduate biology. Journal of educational psychology, 106(2), 375.

Hegarty, N. (2010). Application of the academic motivation scale to graduate school students. The Journal of Human Resource and adult learning, 6(2), 48.

Kessels, U., Heyder, A., Latsch, M., \& Hannover, B. (2014). How gender differences in academic engagement relate to students' gender identity. Educational Research, 56(2), 220-229.

Lepper, M. R., Corpus, J. H., \& Iyengar, S. S. (2005). Intrinsic and extrinsic motivational orientations in the classroom: Age differences and academic correlates. Journal of educational psychology, 97(2), 184.

Makhlough, A., Siamian, H., Asrami, F. N., Khademloo, M., \& Esmaeili, H. (2016). The relationship between academic motivation and academic performance among students at Mazandaran University of Medical Sciences in 2014. International Journal of Humanities and Cultural Studies (IJHCS) ISSN 2356-5926, 1(1), 1419-1426.

McGehee, N. G., Kim, K., \& Jennings, G. R. (2007). Gender and motivation for agri-tourism entrepreneurship. Tourism Management, 28(1), 280-289.

Mega, C., Ronconi, L., \& De Beni, R. (2014). What makes a good student? How emotions, selfregulated learning, and motivation contribute to academic achievement. Journal of educational psychology, 106(1), 121.

Pirmohamed, S., Debowska, A., \& Boduszek, D. (2017). Gender differences in the correlates of academic achievement among university students. Journal of Applied Research in Higher Education, 9(2), 313-324.

Roohi, G. H., Asayesh, H., Bathai, S. A., Shouri Bidgoli, A. R., Badeleh, M. T., \& Rahmani, H. (2013). The relationship between self-efficacy and academic motivation among students of medical sciences. The Journal of Medical Education and Development, 8(1), 45-51.

Sharma, D., \& Sharma, S. (2018). Relationship between motivation and academic achievement. International Journal of Advances in Scientific Research, 4(1), 01-05.

Strayhorn, T. L. (2018). College students' sense of belonging: A key to educational success for all students. Routledge.

Tomlinson, M. (2017). Student perceptions of themselves as 'consumers' of higher education. British Journal of Sociology of Education, 38(4), 450-467.

Vallerand, R. J. (1997). Toward a hierarchical model of intrinsic and extrinsic motivation. In Advances in experimental social psychology (Vol. 29, pp. 271-360). Academic Press.

Vallerand, R. J., Blais, M. R., Briere, N. M., \& Pelletier, L. G. (2002). Construction et validation de l'echelle de motivation 'en education (EME) [Development and validation of the Academic Motivation Scale (AMS)]. ' Canadian Journal of Behavioural Science, 21, 323-349.

Wolters, C. A. (2004). Advancing Achievement Goal Theory: Using Goal Structures and Goal Orientations to Predict Students' Motivation, Cognition, and Achievement. Journal of educational psychology, 96(2), 236.

Zheng, C., Erickson, G. A., Kingston, N. M., \& Noonan, P. M. (2014). The relationship among selfdetermination, self-concept, and academic achievement for students with learning disabilities. Journal of Learning Disabilities, 47(5), 462-474. 